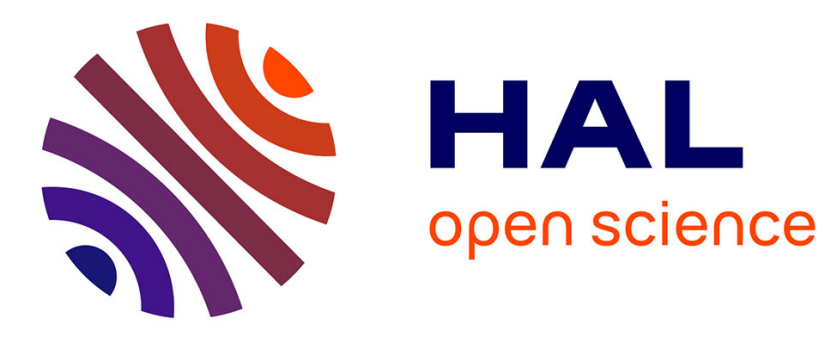

\title{
The role of family incomes in cigarette smoking: Evidence from French students
}

Christian Ben Lakhdar, Grégoire Cauchie, Nicolas Gérard Vaillant, François-Charles Wolff

\section{- To cite this version:}

Christian Ben Lakhdar, Grégoire Cauchie, Nicolas Gérard Vaillant, François-Charles Wolff. The role of family incomes in cigarette smoking: Evidence from French students. 2012. hal-00694336

\section{HAL Id: hal-00694336 \\ https://hal.science/hal-00694336}

Preprint submitted on 4 May 2012

HAL is a multi-disciplinary open access archive for the deposit and dissemination of scientific research documents, whether they are published or not. The documents may come from teaching and research institutions in France or abroad, or from public or private research centers.
L'archive ouverte pluridisciplinaire HAL, est destinée au dépôt et à la diffusion de documents scientifiques de niveau recherche, publiés ou non, émanant des établissements d'enseignement et de recherche français ou étrangers, des laboratoires publics ou privés. 
EA 4272

\title{
The role of family incomes in cigarette smoking: Evidence from French students
}

\author{
Christian Ben Lakhdar* \\ Grégoire Cauchie* \\ Nicolas Gérard Vaillant* \\ François-Charles Wolff**
}

\begin{abstract}
$2012 / 18$
*FLSEG -Université Catholique de Lille et LEM

**EEMNA - Université de Nantes et INED

Laboratoire d'Economie et de Management Nantes-Atlantique

Université de Nantes

Chemin de la Censive du Tertre - BP 52231

44322 Nantes cedex 3 - France

www.univ-nantes.fr/iemn-iae/recherche
\end{abstract}

Tél. +33 (0)2 40141717 - Fax +33 (0)2 40141749 


\title{
The role of family incomes in cigarette smoking: Evidence from French students
}

\author{
Christian Ben Lakhdar ${ }^{*}$, Grégoire Cauchie $^{* *}$, \\ Nicolas Gérard Vaillant ${ }^{\#}$ and François-Charles Wolff ${ }^{\# \#}$
}

February 2012

\begin{abstract}
In this paper, we study the smoking behavior of students aged from 18 to 25 using four cross-section data sets collected in France from 1997 to 2006. We focus on the role played by student income and parental resources. We find that both the probability of smoking and the number of cigarettes smoked are positively correlated to family resources. Among students, only wages earned and transfers received from parents increase smoking participation. However, sensitivity to income remains weak since a rise of $1 \%$ in income of either the students or their parents leads to an increase in smoking prevalence of about $0.15-0.20 \%$.
\end{abstract}

Keywords: cigarette smoking; students; income effects

JEL classification: I1

\footnotetext{
${ }^{*}$ Corresponding author. LEM (UMR 8179 CNRS) and Université Catholique de Lille (FLSEG), 60 bd Vauban, BP109, 59016 Lille Cedex, France.

E-mail: christian.benlakhdar@icl-lille.fr

${ }^{* *}$ LEM (UMR 8179 CNRS) and Université Catholique de Lille (FLSEG), France.

E-mail: gregoire.cauchie@icl-lille.fr

\# LEM (UMR 8179 CNRS) and Université Catholique de Lille (FLSEG), France.

E-mail: nicolas.vaillant@icl-lille.fr http://ngvaillant.e-monsite.com/

\#\# LEMNA, Université de Nantes and INED, Paris, France.

E-mail: francois.wolff@univ-nantes.fr http://www.sc-eco.univ-nantes.fr/ ffcwolff/
} 


\section{Introduction}

Tobacco use is the leading global cause of preventable death according to the World Health Organization (WHO, 2011). Despite the various policies implemented to curb this epidemic, a substantial proportion of adolescents and young adults is still smoking in all European countries. According to the recent European School survey Project on Alcohol and other Drugs report (ESPAD, 2009), the average rate of smoking prevalence in 2007 (defined as cigarette use in the last 30 days) was $29 \%$ in European countries. It is therefore important to explore smoking determinants among young adults. Many studies have shown that tobacco use is influenced not only by price, but also by family characteristics of both the young people concerned and their parents. In this context, changes in family resources are influential factors that are expected to affect the tobacco demand curve.

According to studies published during the 80 s and 90 s, the effect of parental socioeconomic status (SES) was not clear-cut. In the US, about half of the empirical studies have found an inverse relationship between SES and smoking behavior (Borland et al., 1975, Mittelmark et al., 1987, Escobedo et al., 1990, Lowry et al., 1996). Conversely, Headen et al. (1991), Bailey et al. (1993) and Flint et al. (1998) have reached the opposite conclusion. Results from countries like Iceland and Scotland also lead to an unclear pattern between SES and smoking (Thorlindsson et al., 1991, Glendinning et al., 1994). Over recent years the relationship between smoking and SES has changed considerably, as has the culture of smoking. For instance, a significant relationship between parental social and occupational groups and smoking behavior was recently highlighted in France among 17year-olds (OFDT, 2010).

At the same time, there is some evidence that the consumption of tobacco among young people is positively correlated with their own levels of income. In Iceland, income earned through after-school work is positively linked to smoking among adolescents (Thorlindsson et al., 1991). Similar results are reported by Alexander et al. (1983) and Stanton et al. (1994) in Australia and New Zealand respectively. Adolescents with a paid job are more able to afford tobacco. In Scotland, Austria, Finland, Germany, Norway and Wales, 15-year-old adolescents with above-average incomes are more likely to be smokers compared to children with below-average incomes (Griesbach et al., 2003). Cigarette smoking is also positively correlated to pocket money as emphasized in Grizeau et al. (1997), Rissel et al. (1999) and Scragg et al. (2002).

Curiously, very few studies have attempted to take both student and parental resources into account when explaining smoking decisions. This is a crucial issue given the expected positive correlation between the incomes of the two generations. In the context of intergenerational relationships, Altonji et al. (1997) have pointed out that omitting the characteristics of both generations in regressions could lead to biased estimates when explaining gifts received from 
parents. Nonetheless, information on family income is crucial to an understanding of how student income influences cigarette consumption net of the parental income effect.

In this paper, we investigate the relationship between family resources and smoking behavior among students. For that purpose, we consider four repeated cross-sectional data sets obtained in France from 1997 to 2006, with details on family incomes. Drawing on a subsample of about 80,000 students aged from 18 to 25 , we perform an econometric analysis of the decision to smoke and the consumption intensity of smokers. The rest of our paper is organized as follows. Section 2 describes smoking behavior of students in France. In Section 3 we present estimates from Probit and OLS models. In Section 4 we further examine the correlation between smoking and family incomes. Finally, Section 5 concludes.

\section{Description of the data}

We study the role of family incomes on cigarette consumption using repeated cross-sectional data sets aimed at measuring the standard of living of students in France. The Conditions de Vie des Etudiants survey is carried out by the Observatoire de la Vie Etudiante (OVE hereafter) every three years. Founded in 1989 by the French Board of Education, its aim is to highlight students' living conditions and way of life. The data cover the period from 1994 to 2006. The OVE survey includes more than 250 questions related to educational achievement, schooling effort, personal and parental economic resources, family relationships, schedules, etc. Questionnaires were sent by regular mail to a large sample of randomly selected students, with a response rate of about $25 \%$. The overall sample, which is representative of the French student population, includes 131,556 students of all ages.

Students indicate whether they are smoking or not at the time of the survey and how many cigarettes they are smoking per day. In what follows, we focus on both the probability of smoking and the number of cigarettes per day conditional on smoking status. To explain the consumption of cigarettes, we introduce characteristics related to both the student and their parents. We consider the following explanatory variables: gender, age, number of siblings, baccalaureate with distinction and personal resources for the student; and marital status, employment status, education and income for parents. Unfortunately, there is no information on parental smoking behavior in the OVE survey, but we will examine this issue further in Section 4.

The resources of the younger generation are defined as follows. Firstly, students receive wages when they have a job while studying or during vacation. Secondly, students may benefit from several public subsidies or grant transfers in France. For instance, they are eligible for scholarships when parents have limited resources. Students who rent an apartment receive housing allowances. Thirdly, young adults may receive money from their parents. Several studies have highlighted the importance of these private transfers among students, which may come through either regular or 
irregular allowances (Barnet-Verzat and Wolff, 2002). The student's income is defined as the sum of labor income, public grant transfers and parental transfers. The nominal income values were deflated using the French consumer price index, with 2006 prices as the base.

When selecting data, we discarded the 1994 survey $(N=26,551)$ because there was no information on student resources for that year. We have also restricted our analysis to the subsample of students aged 18 to 25 who have completed high school. This deletes 10,552 students. Both younger and older students are likely to show very specific behavior. Young students, for example, have often skipped one or more grades in school and tend to devote much more time to schoolwork. By contrast, older respondents may either be subject to stronger tobacco addiction acquired over their life cycle or less concerned about their physical health. Finally, we discarded another 7,122 observations with missing values and obtained a sample comprising 87,331 students: 24,076 in 1997, 22,213 in 2000, 20,165 in 2003 and 20,877 in 2006.

We provide a description of the sample in Table 1 . There are more female than male students in French universities (62.7\% in 1997, 67.8\% in 2006). The mean age is 20.5 years and more than one-half of the students obtained their high school diploma without distinction. The average income per student is about 490 euros per month over the period (from 452 euros in 1997 to 509 euros in 2006). There are substantial inequalities among students since the median income is around 400 euros. A breakdown of the various sources of income shows that income from work represents $25 \%$ of students' resources, public subsidies $35 \%$ and parental transfers $40 \%$. The weight of these various income sources has not really changed over the period.

$20 \%$ of the students' parents are separated. Over $50 \%$ of them have completed higher education and in $16 \%$ of cases at least one parent is unemployed. Unsurprisingly, parents have much higher resource levels (over six times more) than their children. On average, they earn 3,213 euros per month. We find a statistically significant coefficient of correlation between parental income and child income, but the corresponding coefficient (0.015) is very weak. This is due to the fact that students with poor parents benefit from much larger public subsidies and are more likely to work to earn money. Conversely, the correlation between pocket money and parental income is much higher (0.180).

\section{Insert Table 1 here}

As shown in Figure 1, the proportion of smokers among French students has decreased since 2000: $28.1 \%$ in $1997,28.9 \%$ in $2000,26.3 \%$ in 2003 and $22.9 \%$ in 2006 . This fall in smoking participation could be explained by the multiple increases in the price of tobacco over the period. Between 1997 and 2006, the price of the most sold pack of cigarettes in France increased by $85.2 \%$. A similar pattern is observed in mean consumption of cigarettes per smoker. On average, each student was smoking 10 cigarettes per day in 1997, 9.6 in 2000, 8.8 in 2003 and 8.2 in 2006. 
Insert Figure 1 here

There are only slight differences in smoking behavior between male and female students. In the period under study, the proportion of smokers is respectively $26.4 \%$ for men and $26.9 \%$ for women. The gender gap is around one percent till 2003 and decreases to 0.2 in 2006 . At the same time, male students tend to consume more cigarettes per day than female students, respectively 9.6 cigarettes per smoker as opposed to 9.1. The proportion of smokers increases considerably with age: $19.8 \%$ at $18,25.5 \%$ at $19,27.7 \%$ at $20,29.1 \%$ at 22 and around $31 \%$ above. At the same time, older students smoke more cigarettes per day: eight at age 18, nine at age 20 and more than 10 at age 22 and above.

In Figure 2, we plot the proportion of smokers as a function of income deciles and fit a quadratic profile. Our results indicate that richer students are more likely to smoke. The various income profiles are essentially linear and remain quite stable over time. Conversely, the relationship between students' smoking behavior and parental income is less pronounced. Students are more likely to smoke when their parents are rich, but the sensitivity of smoking to parental resources tends to decrease over the period 1997-2006.

Insert Figure 2

\section{Econometric analysis}

We turn to an econometric analysis to assess the role of incomes on both the probability of smoking and the number of cigarettes smoked. Smoking decisions are expected to depend on a set of family characteristics that includes both the student's and the parents' levels of resources. We turn to Probit models to explain the probability that a student is smoking. Since there may be some nonlinearity in the relationship between income and smoking, we regress smoking as a function of family income quartiles. Marginal effects (estimated at sample means) are reported in Table 2.

We first consider the whole sample and include year-specific dummies. In column $1 \mathrm{~A}$, we only account for the student's characteristics. The average probability of smoking is $26.2 \%$ between 1997 and 2006. This probability was one point higher in 2000 compared with 1997, but it has substantially decreased since then (-1.1 points in 2003, -4.6 points in 2006). We find no significant difference in the probability of smoking between male and female students. We obtain a concave profile between age and smoking, with a peak at 22.5 years. Students who have several siblings and have obtained their high school diploma with distinction are less likely to smoke. Finally, students with more financial resources are much more likely to smoke. The probability of smoking increases by $5.3 \%$ for the second quartile, $8 \%$ for the third quartile and as much as $11.4 \%$ for the fourth quartile. 
We include additional controls related to parental characteristics in column 1B. Negative events faced by parents increase the likelihood of smoking: students are more likely to smoke when their parents do not live together $(+7.4 \%)$ and when they have at least one unemployed parent $(+3 \%)$. A reverse pattern is found when considering parental education and students are more likely to smoke when they have rich parents. Their probability of smoking is $3.6 \%$ higher with parents in the second quartile of income, $4.4 \%$ in the third quartile and $6.9 \%$ in the fourth quartile. At the same time, taking parental characteristics into account has very little influence on the marginal effects of the student's covariates.

We then estimate year-specific Probit regressions (columns 2A-5B). Our results remain remarkably stable over time. We observe no difference between male and female students, while having unemployed, separated or highly educated parents increases the likelihood of smoking. Our main finding is the strong correlation between smoking decisions and family income. The probability of smoking is much higher for children in the upper quartiles of income. For children in the fourth quartile, it increases by $10.6 \%$ in $1997,10.5 \%$ in $2000,11.9 \%$ in 2003 , and $9.9 \%$ in 2006 . The marginal effect of parental income is slightly lower for the highest quartile: $10.4 \%$ in $1997,5.9 \%$ in $2000,7.3 \%$ in 2003 and $6 \%$ in 2006.

Next, we estimate OLS regressions to explain the number of cigarettes (Table 3). We choose to focus on the subsample of smokers, meaning that we put aside the selectivity issue. As shown in column $1 \mathrm{~A}$, the consumption of cigarettes per smoker has significantly decreased over time in France: - 0.43 in 2000 compared to 1997, -1.23 in 2003 and -1.82 in 2006. Girls tend to smoke fewer cigarettes than boys (-0.4 on average). The number of cigarettes strongly increases with age, but it decreases with high school distinction. Again, we observe a positive correlation between student resources and tobacco consumption. On average, the average consumption increases by 0.76 cigarette for students in the second income quartile, 1 in the third quartile and 1.3 in the fourth quartile.

Insert Table 3 here

The OLS coefficients associated with student income are slightly lower when we introduce parental characteristics into the regressions, but the relationship between cigarettes and student resources remains highly significant (column 1B). Students whose parents do not live together or are unemployed consume more cigarettes per day. Conversely, parental education has no significant influence on tobacco consumption. Finally, we observe that children smoke more cigarettes only when their parents are in the top quartile of income distribution ( +0.52 cigarette). There is no significant difference in tobacco consumption between students when their parents are in the first three quartiles of income. 
A few differences appear when considering year-specific regressions (columns 2A-5B). We find a decreasing gap in tobacco consumption between male and female students over the period. Having siblings has not influenced the number of cigarettes smoked since 2000. For the four years under consideration, students smoke more cigarettes when they have more income. Since 2000, students in the upper quartile of income smoke about one additional cigarette compared to children in the first quartile. Conversely, parental resources progressively lose their influence over the period. Consumption was increased by 0.55 cigarette in 1997 and 0.8 cigarette in 2000 with parents in the fourth quartile of income, but the relationship is no longer significant in 2006 (column 5B).

We turn to elasticity to further assess the sensitivity of smoking to family income. As the relationship between smoking and income is nonlinear according to Table 2, we replace the quartile dummies by cubic polynomials for income both in the Probit and OLS models. We calculate the elasticities at the sample means of the other covariates and present our results in Table 4.

Insert Table 4 here

We first consider income elasticity of smoking participation. Over the whole period, we find that a $1 \%$ rise in student income increases the probability of smoking by $0.178 \%$ (row $1 \mathrm{~A}$ ). Adding parental characteristics has little influence on the elasticity of participation, which decreases slightly to 0.163 . At the same time, we observe a very similar value (0.159) for parental income participation elasticity. The sensitivity of smoking decisions to student income increased slightly from 1997 to 2006. With respect to a rise of $1 \%$ in student's real income, the likelihood of smoking increased by $0.152 \%$ in $1997,0.168 \%$ in $2000,0.195 \%$ in 2003 and $0.196 \%$ in 2006 . Parental income elasticity is of similar magnitude in 2003 and 2006.

We obtain much lower values for income elasticity of cigarette consumption. Using OLS estimates, we find that a $1 \%$ increase in a student's income leads to a rise of $0.06 \%$ in cigarette consumption (row $1 \mathrm{C}$ ). Again, the sensitivity of tobacco consumption to income does not vary greatly over the period. The income elasticity of smoking was 0.066 in 1997, 0.055 in 2000, 0.068 in 2003 and 0.049 in 2006. As for smoking participation, we get similar values for the elasticity of cigarette consumption in terms of student and parent incomes (row 1D).

The decision to smoke is more sensitive to personal resources for male than for female students (Table 4). A $1 \%$ rise in income increases the probability of smoking by 0.146 for boys and 0.196 for girls (rows $2 \mathrm{~A}$ and $3 \mathrm{~A}$ ). These values slightly decrease to 0.137 and 0.177 when parental characteristics are introduced as additional explanatory variables (rows $2 \mathrm{~B}$ and $3 \mathrm{~B}$ ). The gender difference in participation elasticity was much higher at the end than at the beginning of the period. Conversely, there is little difference in parental income elasticity of smoking participation ( 0.158 for boys, 0.162 for girls). 
A difficulty with the OLS income-smoking estimates is that they do not take into account the selection problem due to the focus on a subsample of smokers. A possible solution here could be a Heckman selection model (Heckman, 1979), but the difficulty in our context is to find relevant exclusion restrictions. Any variable expected to affect the decision to smoke is likely to influence the number of cigarettes. We thus choose to rely on the method proposed by Altonji et al. (2011), which allows estimation of the effect of changes in a vector of observable covariates on a limited dependent variable when the latter is a general non-separable function of the selected covariates and the unobservables.

For the presentation, let $S$ be the number of cigarettes smoked, and $Y_{p}$ and $Y_{k}$ respectively the parents' and student's levels of resources. We consider a linear specification of the form:

$$
S=\alpha_{k} Y_{k}+\alpha_{p} Y_{p}+X \beta+\varepsilon
$$

with $X$ the other family background characteristics and $\varepsilon$ a random perturbation. By definition, the OLS coefficients of (1) from the sample of smokers give the uncorrected derivative $\frac{\partial E(S \mid S>0)}{\partial Y_{k}}=\alpha_{k}$ and $\frac{\partial E(S \mid S>0)}{\partial Y_{p}}=\alpha_{p}$. However, we are interested in estimating the derivatives $E\left(\frac{\partial S}{\partial Y_{k}} \mid S>0\right)$ and $E\left(\frac{\partial S}{\partial Y_{p}} \mid S>0\right)$. Following Altonji et al. (2011), it can be shown that (for $i=k, p$ ):

$$
E\left(\frac{\partial S}{\partial Y_{i}} \mid S>0\right)=\frac{\partial E(S \mid S>0)}{\partial Y_{i}}-E(S \mid S>0)\left(-\frac{\partial \operatorname{Pr}(S>0) / \partial Y_{i}}{\operatorname{Pr}(S>0)}\right)
$$

To estimate the selectivity-corrected derivative, we first obtain the uncorrected derivative $\frac{\partial E(S \mid S>0)}{\partial Y_{i}}$ from an OLS regression of the consumption of cigarettes on smokers. Using these OLS estimates, we also deduce the mean number of cigarettes per smoker $E(S \mid S>0)$, which is part of the correction term on the right-hand side of (2). Secondly, from Probit estimates of the smoking participation, we deduce the mean estimated probability of smoking $\operatorname{Pr}(S>0)$ along with the derivatives $\frac{\partial \operatorname{Pr}(S>0)}{\partial Y_{i}}$. The combination of these various terms leads to the selectivity-corrected smoking-income derivatives $E\left(\frac{\partial S}{\partial Y_{i}} \mid S>0\right)$. We rely on a bootstrapping method to obtain standard errors for the corrected derivative.

We present results from a specification with linear incomes in Table 5, a very similar pattern being found when considering polynomials in family income. The uncorrected derivatives $\frac{\partial E(S \mid S>0)}{\partial Y_{i}}$ are all positive for the various years. Since $\frac{\partial \operatorname{Pr}(S>0)}{\partial Y_{k}}>0$ and $\frac{\partial \operatorname{Pr}(S>0)}{\partial Y_{p}}>0$ from Table 2, the correction term in (2) is positive both for the student and for parents. The corrected derivative $E\left(\frac{\partial S}{\partial Y_{i}} \mid S>0\right)$ is hence always larger than the uncorrected derivative $\frac{\partial E(S \mid S>0)}{\partial Y_{i}}$. As shown in Table 5, the correction is substantial. 


\section{Insert Table 5}

Over the period, the corrected derivative for both generations is about four times higher than the uncorrected one: 0.585 instead of 0.147 for parents, 2.252 instead of 0.542 for students. We note that the correction factor is slightly higher at the end of the period, at a time when the consumption of cigarettes was less influenced by family income. For children, the smoking-income corrected derivative is multiplied by 3.49 in 1997, 3.27 in 2000, 4.33 in 2003 and 6.91 in 2006.

\section{Discussion and interpretation}

A first result of our econometric analysis is the positive correlation between the probability of smoking and student resources. Nevertheless, the sensitivity of smoking participation to income remains weak since a $1 \%$ income increase leads to a rise in smoking prevalence which is between $0.15 \%$ and $0.2 \%$ across the period. A simple interpretation is that richer children can afford to buy costly cigarettes.

Although there is no causality in our analysis, it seems interesting to see whether specific resources have a greater influence on the smoking decision. We expect children to have a higher probability of buying cigarettes (and thus smoking) when they have more money of their own. This suggests that smoking participation should be much more sensitive to income from paid work and pocket money than public allowances. By definition, these grant transfers are targeted to welldefined spending like housing benefits and scholarship, and so should not influence tobacco expenditure. We thus reestimate the Probit regressions of Table 2 by replacing the student's total income by its three components.

Our results (not reported) show that only wages and parental transfers have a significant influence on tobacco prevalence over the period. Conversely, the coefficient associated with public subsidies is nearly zero and absolutely not significant. Thus students are enabled to smoke more often only by the money obtained either from a paid job or from their parents. Moreover the income elasticity of participation is very similar when a student either earns higher wages or receives larger private transfers. Similar results are found for cigarette consumption among smokers, which increases only with the resources that students earn themselves.

A second finding is that an increase in student income has a more marked effect on the probability of smoking than on the consumption of cigarettes. According to Table 4, the income elasticity of smoking participation is about three times higher than the income elasticity of cigarette consumption. A simple explanation is that tobacco consumption is addictive among students. Once students begin to smoke, they experience difficulties in giving up the habit. As a consequence, their cigarette purchases would not be very sensitive to their own resources. From a public policy 
viewpoint, this is a crucial issue as it suggests that anti-smoking strategies must focus on preventing students (and younger children) from starting to smoke cigarettes.

Another result is that the restriction to the subsample of smokers without considering selectivity bias leads to underestimated income coefficients. As a consequence, we obtain higher values for the elasticity of tobacco consumption with respect to the student's and parental income, around 0.15 in both cases (Table 5). Nonetheless demand for cigarettes among smokers still increases much less than proportionally as family income rises.

The last result of importance is that students are more likely to smoke and consume more cigarettes not only when they have greater resources, but also when their parents are themselves rich. Before trying to provide some intuition for the latter positive correlation, we must discuss one serious drawback for our data, which is the lack of information about parental smoking habits. Suppose that throughout the life cycle the probability of smoking increases with income. In that case, we expect rich parents to have a higher probability of smoking. This should have a direct impact on the student's tobacco prevalence through the intergenerational transmission of smoking habits.

This discussion makes it clear that the effect of parental income on student smoking behavior is likely to be overstated since we do not account for parental smoking in our regressions. The question is whether or not inclusion of parental smoking could render the parental income coefficient no longer statistically significant. Since by definition the OVE survey does not include parental tobacco consumption, we decided to enrich our analysis by matching our data with another survey that sheds light on smoking behavior of adults of every age. Specifically, we consider the Health and Medical Care survey (HMC) conducted in 2003 on a sample of about 12,000 households. The Health survey includes questions about smoking habits. It is conducted every 11 years in France $(1981,1992,2003)$, so that we were unable to perform the same analysis for the three other years under consideration $(1997,2000,2006)$.

We proceed in the following way. First, we select only household heads and their spouse (if any) aged between 45 and 65 . This is approximately the age group of the parents of our sample of students. Next, at the household level, we construct variables indicating whether parents live together as a couple or not, the level of education of the head of the household with five categories, and total spousal income with 50 categories. We then combine these three covariates to form a large set of groups for which we calculate an average probability of smoking. We define a couple as smoking if at least one spouse reports tobacco consumption. Finally, we form similar groups using the 2003 OVE data from living as a couple, and from the education and income status of parents, then match the OVE and HMC data sets over these groups. Our measure of smoking habits for a parent is hence the average probability of smoking calculated from her reference group. 
Results from Probit models estimated on the matched sample are presented in Table 6. As expected, we obtain a positive correlation (significant at the 1 percent level) between parental smoking and the student's tobacco prevalence. At the means of the selected covariates, the probability for a student to smoke increases by six percentage points (thus a rise of $23.5 \%$, since the predicted probability of smoking is $25.6 \%$ ). Another finding is that inclusion of parental smoking habits has almost no influence on the income coefficients of both generations. With cubic profiles for income, the elasticity of smoking participation with respect to parental resources is, for instance, about 0.18 both with and without parental smoking.

Insert Table 6

These results must, of course, be interpreted with caution as we only account for parental smoking at an aggregate level through our matching procedure. In what follows, we consider three explanations, not necessarily exclusive, that could explain why parental income has a direct influence on the student's decision to smoke (net of parental smoking behavior) in our data.

A first possibility is that parental income picks up a milieu effect which would be imperfectly measured in our previous regressions. Since students have by definition not yet completed their education, it is somewhat difficult to take adequate account of their socio-economic status. When we choose to add the occupations of both the father and mother into the smoking participation equation, we find that parental occupation significantly affects the probability that a student reports smoking. Furthermore, these additional controls lower the parental income coefficient. The income elasticity of smoking participation is 0.116 when occupations are included, which is $27 \%$ lower compared to the elasticity without occupation (0.159). At the same time, parental occupation leaves the participation elasticity with respect to the student's income unchanged ( 0.162 instead of 0.163 ).

A second possibility is that children from rich families are less subject to parental control. For instance, parents could spend less time monitoring their children because they face severe job time constraints. Unfortunately, the OVE survey does not include any information about the number of hours worked by parents. We decide to account for the residential status of the student as a proxy of the time that students and their parents live together. Parents have certainly less control over their children's behavior (including smoking) when the latter live in an independent dwelling.

Results (not reported) show that students have lower smoking probability when they live with their parents (at the one percent level). The predicted probability of smoking decreases by around two percent when the student lives in the parental home. However, there is little difference in the sensitivity of smoking participation to parental resources depending on where students live. Parental income elasticity is 0.128 when students co-reside and 0.109 when they live independently. It is nonetheless difficult to interpret these results as the distribution of family incomes has itself an influence on the decision to leave parents (Le Blanc and Wolff, 2006). 
A last possibility is that our income variables suffer from measurement errors, especially among students. While most of them (80\%) receive pocket money from their parents, these gifts are likely to under-represent the true support provided by parents. Very often, students report in the OVE survey that their parents pay some of their expenses directly. This happens for instance for school fees $(68 \%$ of students are concerned), health costs $(60 \%)$, clothes $(55 \%)$, car expenses $(47 \%)$, but much less often for outings with friends (21\%). Although there is no information on the amount that parents pay monthly, it follows that students who benefit from such direct parental payments should have more money of their own to spend on personal expenses.

A brief look at the data confirms that students have higher smoking probability when their own parents directly pay some of their expenses. Of course, rich parents are much more likely to provide such direct financial help. At the same time, children who benefit from these direct payments may have fewer resources than others since they need less money for their current living expenses. Although data constraints mean we cannot go further in that direction, the positive correlation between smoking and parental income may hence pick up additional parental transfers that are not totally measured in the OVE survey.

\section{Conclusion}

In this paper, we have analyzed the smoking behavior of about 80,000 university students in France, with a focus on the role played by family resources. We find that student income has a significant effect on smoking behavior. However, sensitivity to income remains limited since a rise of one percent in income leads to an increase in smoking prevalence of about $0.15-0.20 \%$ across the period. It is only wages and transfers from parents that are positively correlated with smoking participation. Among smokers, students with more money also smoke slightly more cigarettes. Finally, parental characteristics affect the smoking prevalence of adolescents since students with highly educated and rich parents have an increased probability of smoking.

Interpretation of our results is obvious when considering the positive effect of student income. With more money of their own, they can more easily afford cigarettes. The role played by parental income is more challenging as it remains net of student income. We suggest that this positive correlation is not due to parental smoking habits or to a lower level of control of their children's behavior by richer parents, but our findings have to be cautiously interpreted because of data constraints. Alternative interpretations are that parental income picks up a milieu effect which is not totally captured by parental education or that students benefit from many expenses paid by their parents directly. Although such transfers are not considered pocket money by their recipients, there is no doubt that they affect the amount of money that students may devote to personal consumption, leisure activities and tobacco purchase. 
Certain caveats must be kept in mind when interpreting our results. First, it would be useful to have data with both the joint distribution of family income and parental smoking habits. Our matching procedure is an attempt to take parental behavior into account, but it would certainly help to know whether parents smoke or not. Secondly, data on smoking decisions of siblings would be helpful to take unobserved heterogeneity into account through the estimation of family fixed effect models. Thirdly, having longitudinal data would enable better investigation of the effects of income changes over time as well as the introduction of the role of past tobacco consumption on current consumption. While such data does not exist in France, long panel data sets existing in Germany, United States or United Kingdom represent opportunities that we will consider for future work.

In terms of public policy implications, the limited impact of family income on smoking behavior among students is an important result. It suggests that the substantial increase in tobacco prices during recent years in France has had only a moderate effect on consumption. In fact, very recent results have even shown that the smoking prevalence rate increased by $2 \%$ between 2005 and 2010, especially among women and unemployed people (Beck et al., 2010). Since our results show that tobacco consumption is less sensitive to income than smoking participation, the primary aim of control policies should be to prevent young students from beginning tobacco consumption. Since money does not play a very large part, it would be of interest to assess the impact on the student population of such alternative policies as visual warnings on cigarette and tobacco packs. 


\section{References}

Alexander H.M., Callcott R., Dobson A.J., Hardes G.R., Lloyd D.M., O'Connell D.L., (1983), “Cigarette smoking and drug use in schoolchildren: IV - Factors associated with changes in smoking behaviour", International Journal of Epidemiology, vol. 12, pp. 59-66.

Altonji J.G., Hayashi F., Kotlikoff L.J. (1997), “Parental altruism and inter vivos transfers: Theory and evidence", Journal of Political Economy, vol. 105, pp. 1121-1166.

Altonji J.G., Ichimura H., Otsu T., (2011), "Estimating derivatives in nonseparable models with limited dependent variables", Econometrica, forthcoming.

Bailey S.L., Ennett S.T., Ringwalt C.L. (1993), "Potential mediators, moderators, or independent effects in the relationship between parents' former and current cigarette use and their children's cigarette use", Addictive Behaviors, vol. 18, pp. 601-621.

Barnet-Verzat C., Wolff F.C. (2002), "Motives for pocket money allowances and family incentives", Journal of Economic Psychology, vol. 23, pp. 339-366.

Beck F., Guignard R., Richard J.-B., Wilquin J.-L., Peretti-Watel P., (2010), "Premiers résultats du baromètre santé 2010. Evolutions récentes du tabagisme en France", mimeo, INPES.

Borland B.L., Rudolph J.P. (1975), "Relative effects of low socio-economic status, parental smoking and poor scholastic performance on smoking among high school students", Social Science and Medecine, vol. 9, pp. 27-30.

Escobedo L.G., Anda R.F., Smith P.F., Remington P.L., Mast E.E. (1990), "Sociodemographic characteristics of cigarette smoking initiation in the United States", Journal of the American Medical Association, vol. 264, pp. 1550-1555.

ESPAD, (2009), The 2007 ESPAD Report - Substance Use Among Students in 35 European Countries, CAN, EMCDDA, Pompidou Group, 406 p.

Flint A.J., Yamada E.G., Novotny T.E. (1998), "Black-white differences in cigarette smoking uptake: progression from adolescent experimentation to regular use", Preventive Medicine, vol. 27, pp. 358364.

Glendinning A., Shucksmith J., Hendry L. (1994), "Social class and adolescent smoking behavior", Social Science and Medicine, vol. 38, pp. 1449-1460.

Griesbach D., Amos A., Currie C. (2003), "Adolescent smoking and family structure in Europe", Social Science and Medicine, vol. 56, pp. 41-52.

Grizeau D., Baudier F., Allemand H. (1997), "Opinions et comportements des adolescents français face au tabac en 1995", Archives de Pédiatrie, vol. 4, pp. 1079-1086.

Headen S.W., Bauman K.E., Deane G.D., Koch G.G. (1991), "Are the correlates of cigarette smoking initiation different for Black and White adolescents ?", American Journal of Public Health, vol. 81, pp. 854-858.

Heckman J., (1979), "Sample selection bias as a specification error", Econometrica, vol. 47, pp. 153-61.

Le Blanc D., Wolff F.C., (2006), "Leaving the parental home: The role of parent's and child's incomes", Review of Economics of the Household, vol. 4, pp. 53-73.

Lowry R., Kann L., Collins J.L., Kolbe L.J. (1996), "The effect of socioeconomic status on chronic disease risk behaviors among US adolescents", Journal of the American Medical Association, vol. 276, pp. 792797.

Mittelmark M.B., Murray D.M., Luepker R.V., Pechacek T.F., Pirie P.L., Pallonen U.E. (1987), "Predicting experimentation with cigarettes: the childhood antecedents of smoking study (CASS)", American Journal of Public Health, vol. 77, pp. 206-208. 
OFDT, (2010), Drogues: Chiffres-Clés, OFDT, Saint-Denis.

Rissel C., McLellan L., Bauman A. (1999), "Factors associated with delayed tobacco uptake among Vietnamese/Asian and Arabic youth in Sydney, NSW", Australian and New Zealand Journal of Public Health, vol. 24, pp. 22-28.

Scragg R., Laugesen M., Robinson E. (2002), "Cigarette smoking, pocket money and socioeconomic status: results from a national survey of $4^{\text {th }}$ form students in 2000", Journal of the New Zealand Medical Association, vol. 115, pp. 1-8.

Stanton W.R., OeiT.P., Silva P.A., (1994), "Sociodemographic characteristics of adolescent smokers", International Journal of the Addictions, vol. 29, pp. 913-925.

Thorlindsson T., Vilhjalmsson R. (1991), "Factors related to cigarette smoking and alcohol use among adolescents", Adolescence, vol. 26, pp. 399-418.

WHO (2011). WHO report on the global tobacco epidemic, Geneva. 
Figure 1. Smoking behavior of students 1997-2006

A. Proportion of students smoking

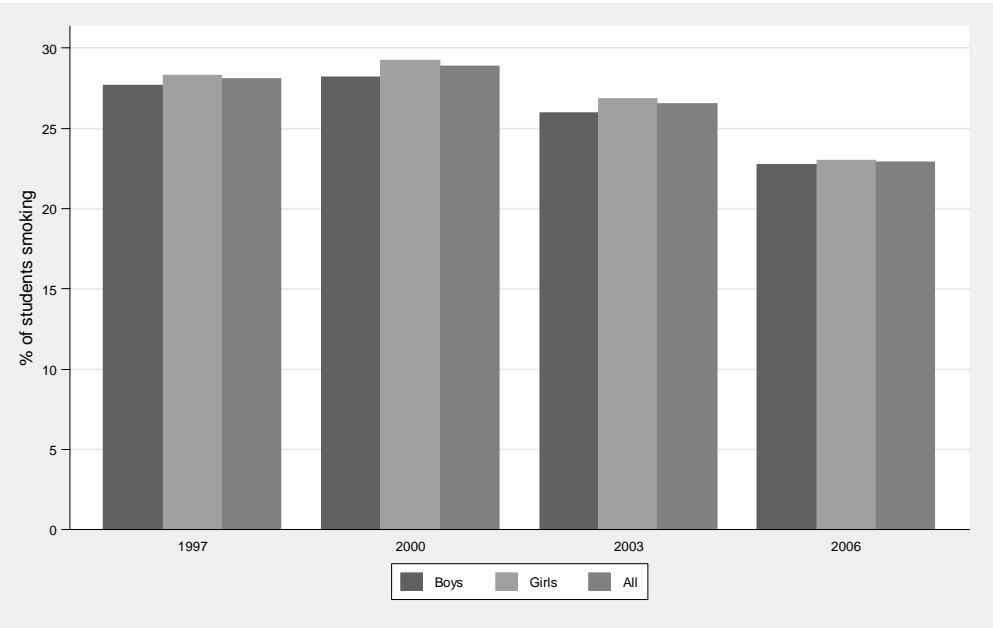

B. Number of cigarettes per smoker

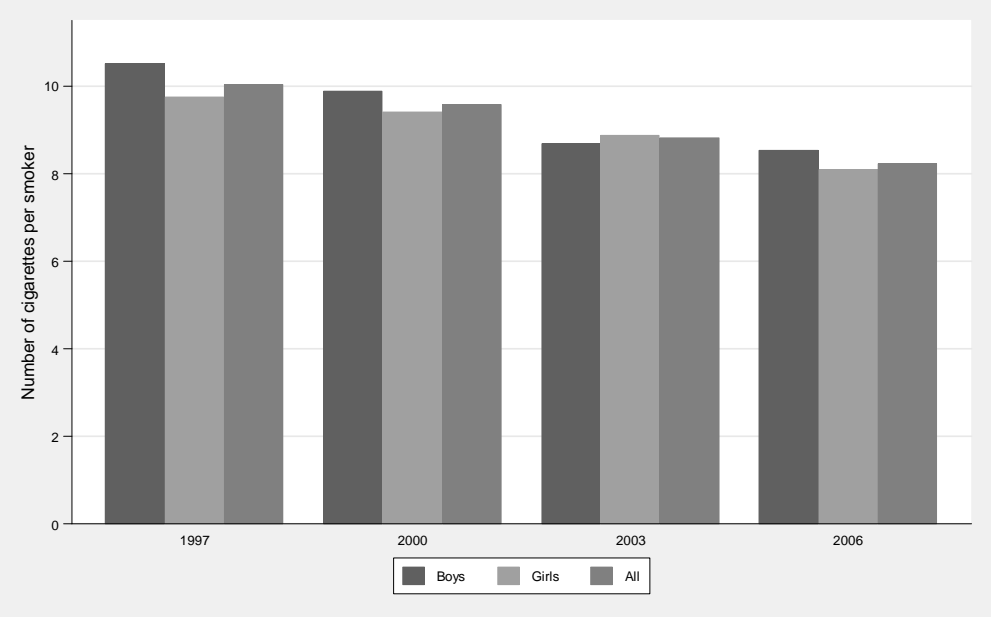

Source: survey OVE 1997-2006. 
Figure 2. Smoking behavior of students, by decile of income 1997-2006 A. By students' income

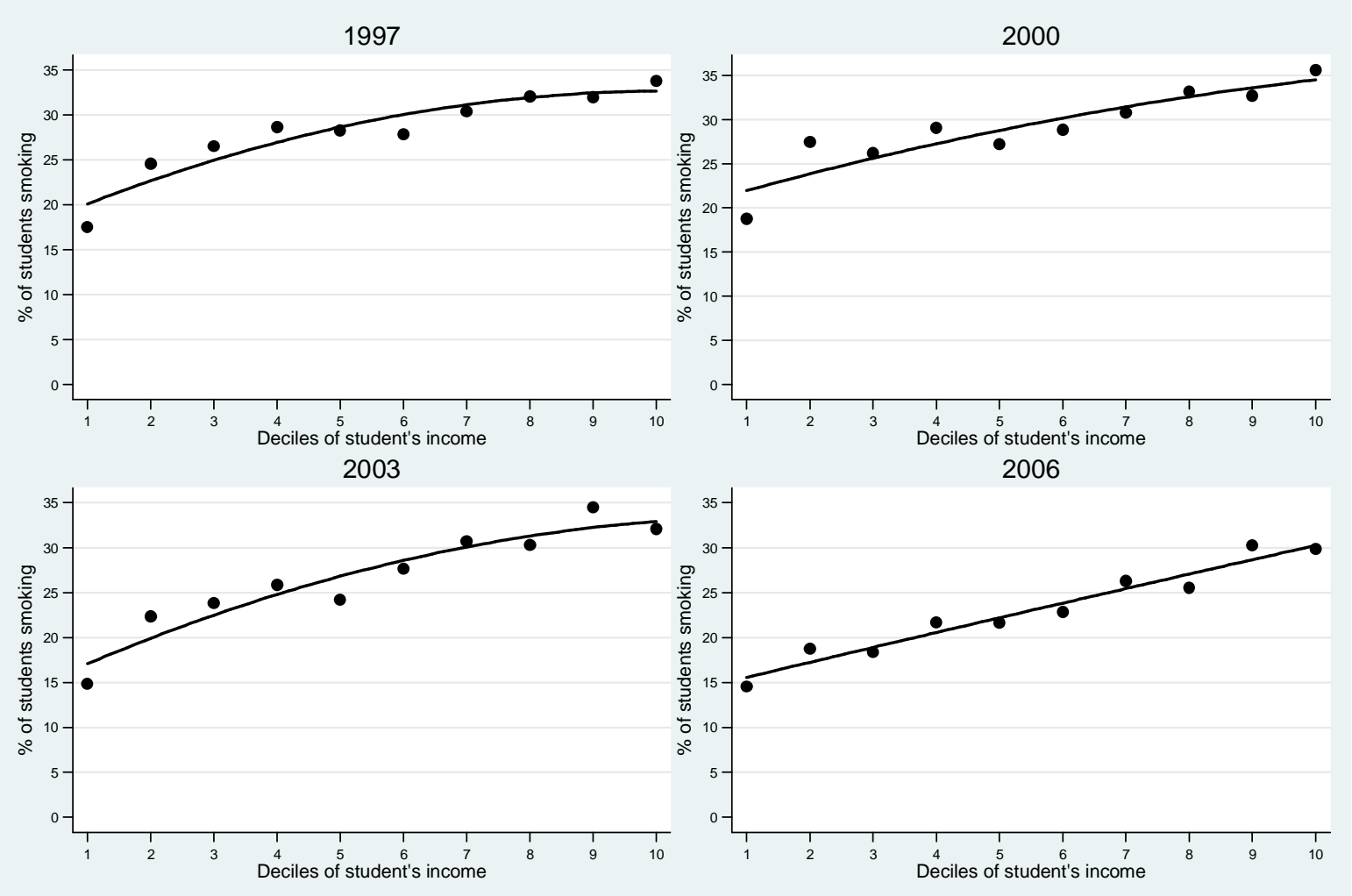

B. By parental income
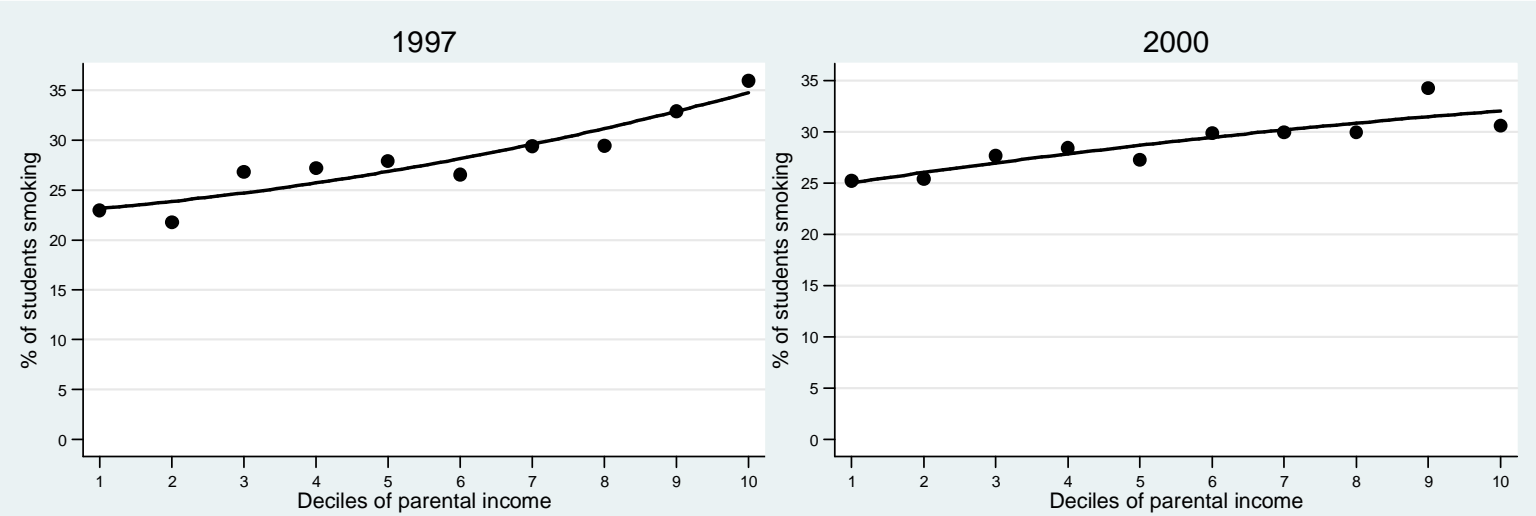

2003

2006
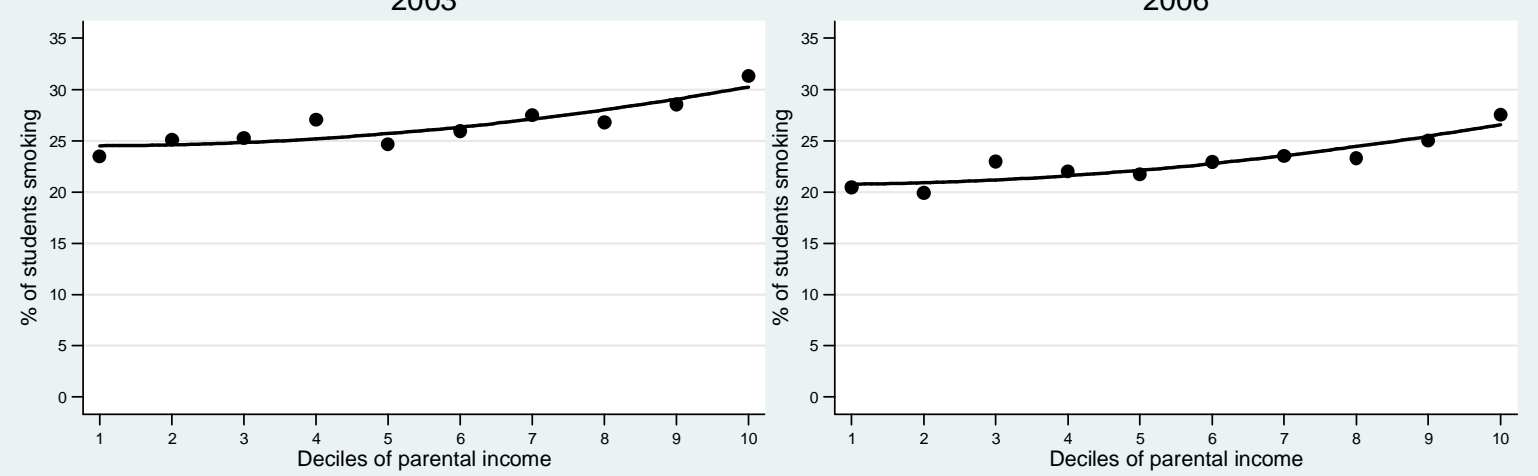

Source: survey OVE 1997-2006. 
Table 1. Descriptive statistics of the sample

\begin{tabular}{|c|c|c|c|c|c|c|}
\hline \multicolumn{2}{|l|}{ Variables } & 1997 & 2000 & 2003 & 2006 & 1997-2006 \\
\hline \multicolumn{7}{|c|}{ Student's characteristics } \\
\hline \multicolumn{2}{|c|}{ Girls } & 0.627 & 0.636 & 0.664 & 0.678 & 0.650 \\
\hline \multicolumn{2}{|l|}{ Age } & 20.529 & 20.449 & 20.354 & 20.450 & 20.449 \\
\hline \multicolumn{2}{|c|}{ Number of siblings } & 1.660 & 1.684 & 1.747 & 1.732 & 1.703 \\
\hline \multirow[t]{4}{*}{ High school } & Without distinction & 0.635 & 0.576 & 0.555 & 0.522 & 0.574 \\
\hline & Cum laude & 0.259 & 0.279 & 0.283 & 0.298 & 0.279 \\
\hline & Magna cum laude & 0.088 & 0.114 & 0.124 & 0.144 & 0.116 \\
\hline & Summa cum laude & 0.019 & 0.031 & 0.039 & 0.037 & 0.031 \\
\hline \multirow[t]{2}{*}{ Labor income } & Mean & 101.442 & 131.032 & 135.449 & 135.005 & 124.844 \\
\hline & St. deviation & 244.497 & 284.483 & 280.288 & 287.354 & 274.141 \\
\hline \multirow[t]{2}{*}{ Public subsidies } & Mean & 171.907 & 164.844 & 168.232 & 179.843 & 171.159 \\
\hline & St. deviation & 260.395 & 214.182 & 212.617 & 226.769 & 230.481 \\
\hline \multirow[t]{2}{*}{ Private transfers } & Mean & 178.355 & 194.708 & 211.301 & 194.438 & 193.967 \\
\hline & St. deviation & 219.966 & 353.576 & 466.150 & 365.865 & 356.992 \\
\hline \multirow[t]{2}{*}{ Total income } & Mean & 451.704 & 490.583 & 514.982 & 509.286 & 489.970 \\
\hline & St. deviation & 402.270 & 475.602 & 555.098 & 500.520 & 483.542 \\
\hline \multicolumn{2}{|c|}{ Labor income/total income } & 0.225 & 0.267 & 0.263 & 0.265 & 0.255 \\
\hline \multicolumn{2}{|c|}{ Public subsidies/total income } & 0.380 & 0.336 & 0.327 & 0.353 & 0.349 \\
\hline \multicolumn{2}{|c|}{ Private transfers/total income } & 0.395 & 0.397 & 0.410 & 0.382 & 0.396 \\
\hline \multicolumn{7}{|c|}{ Parental characteristics } \\
\hline \multicolumn{2}{|c|}{ Parents living separately } & 0.199 & 0.209 & 0.221 & 0.199 & 0.206 \\
\hline \multicolumn{2}{|l|}{ Unemployed } & 0.166 & 0.168 & 0.158 & 0.161 & 0.163 \\
\hline \multirow[t]{5}{*}{ Education } & Primary school & 0.157 & 0.118 & 0.094 & 0.082 & 0.115 \\
\hline & Secondary education & 0.143 & 0.133 & 0.126 & 0.127 & 0.133 \\
\hline & Vocational school & 0.223 & 0.222 & 0.222 & 0.243 & 0.227 \\
\hline & High school & 0.212 & 0.244 & 0.263 & 0.265 & 0.244 \\
\hline & More than high school & 0.265 & 0.283 & 0.295 & 0.284 & 0.281 \\
\hline \multirow[t]{2}{*}{ Total income } & Mean & 3256.123 & 2944.184 & 3506.408 & 3165.689 & 3212.953 \\
\hline & St. deviation & 1829.424 & 1967.946 & 1898.888 & 1687.347 & 1860.143 \\
\hline \multicolumn{2}{|c|}{ Number of observations } & 24076 & 22213 & 20165 & 20877 & 87331 \\
\hline
\end{tabular}

Source: survey OVE 1997-2006. 
Table 2. Probit estimates of the probability of smoking - marginal effects

\begin{tabular}{|c|c|c|c|c|c|c|c|c|c|c|c|}
\hline \multirow{2}{*}{\multicolumn{2}{|c|}{ Variables }} & \multicolumn{2}{|c|}{$1997-2006$} & \multicolumn{2}{|c|}{1997} & \multicolumn{2}{|c|}{2000} & \multicolumn{2}{|c|}{2003} & \multicolumn{2}{|c|}{2006} \\
\hline & & $(1 \mathrm{~A})$ & (1B) & $(2 \mathrm{~A})$ & (2B) & $(3 \mathrm{~A})$ & (3B) & $(4 A)$ & (4B) & $(5 A)$ & (5B) \\
\hline \multicolumn{12}{|c|}{ Student's characteristics } \\
\hline \multicolumn{2}{|l|}{ Girls } & 0.003 & 0.004 & 0.003 & 0.006 & 0.004 & 0.006 & 0.002 & 0.002 & 0.001 & 0.002 \\
\hline \multicolumn{2}{|l|}{ Age } & $0.127^{* * *}$ & $0.136^{* * *}$ & $0.073^{* *}$ & $0.087^{* * *}$ & $0.158 * * *$ & $0.168^{* * *}$ & $0.167^{* * *}$ & $0.180^{* * *}$ & $0.108 * * *$ & $0.108^{* * *}$ \\
\hline \multicolumn{2}{|c|}{ Age squared (/100) } & $-0.003 * * *$ & $-0.003 * * *$ & $-0.002 * *$ & $-0.002 * * *$ & $-0.004 * * *$ & $-0.004 * * *$ & $-0.004 * * *$ & $-0.004 * * *$ & $-0.002 * * *$ & $-0.002 * * *$ \\
\hline \multicolumn{2}{|c|}{ Number of siblings } & $-0.011 * * *$ & $-0.009 * * *$ & $-0.011 * * *$ & $-0.007 * * *$ & $-0.012 * * *$ & $-0.010 * * *$ & $-0.015^{* * *}$ & $-0.013 * * *$ & $-0.007 * * *$ & $-0.005 * *$ \\
\hline \multirow[t]{4}{*}{ High school } & Without distinction & Ref & Ref & Ref & Ref & Ref & Ref & Ref & Ref & Ref & Ref \\
\hline & Cum laude & $-0.047 * * *$ & $-0.053 * * *$ & $-0.037 * * *$ & $-0.045 * * *$ & $-0.056 * * *$ & $-0.063 * * *$ & $-0.047^{* * *}$ & $-0.054 * * *$ & $-0.050 * * *$ & $-0.054 * * *$ \\
\hline & Magna cum laude & $-0.095 * * *$ & $-0.106 * * *$ & $-0.094 * * *$ & $-0.107 * * *$ & $-0.087 * * *$ & $-0.100 * * *$ & $-0.119 * * *$ & $-0.129 * * *$ & $-0.085 * * *$ & $-0.093 * * *$ \\
\hline & Summa cum laude & $-0.156 * * *$ & $-0.168 * * *$ & $-0.134 * * *$ & $-0.149 * * *$ & $-0.193 * * *$ & $-0.205^{* * *}$ & $-0.162 * * *$ & $-0.173 * * *$ & $-0.127 * * *$ & $-0.138 * * *$ \\
\hline \multirow[t]{4}{*}{ Income } & Quartile 1 & Ref & Ref & Ref & Ref & Ref & Ref & Ref & Ref & Ref & Ref \\
\hline & Quartile 2 & $0.053^{* * *}$ & $0.055^{* * *}$ & $0.065 * * *$ & $0.069 * * *$ & $0.044^{* * *}$ & $0.049 * * *$ & $0.060 * * *$ & $0.061 * * *$ & $0.041^{* * *}$ & $0.043 * * *$ \\
\hline & Quartile 3 & $0.080 * * *$ & $0.082^{* * *}$ & $0.075^{* * *}$ & $0.082 * * *$ & $0.069 * * *$ & $0.071 * * *$ & $0.101^{* * *}$ & $0.103^{* * *}$ & $0.073 * * *$ & $0.074 * * *$ \\
\hline & Quartile 4 & $0.114^{* * *}$ & $0.106^{* * *}$ & $0.115^{* * *}$ & $0.106 * * *$ & $0.111 * * *$ & $0.105^{* * *}$ & $0.127^{* * *}$ & $0.119 * * *$ & $0.107 * * *$ & $0.099 * * *$ \\
\hline \multicolumn{12}{|c|}{ Parental characteristics } \\
\hline \multicolumn{2}{|c|}{ Living alone } & & $0.074^{* * *}$ & & $0.095^{* * *}$ & & $0.063 * * *$ & & $0.077^{* * *}$ & & $0.064 * * *$ \\
\hline \multicolumn{2}{|l|}{ Unemployed } & & $0.030 * * *$ & & $0.037^{* * *}$ & & $0.026^{* * *}$ & & $0.027 * * *$ & & $0.032 * * *$ \\
\hline \multirow[t]{5}{*}{ Education } & Primary school & & Ref & & Ref & & Ref & & Ref & & Ref \\
\hline & Secondary education & & $0.043^{* * *}$ & & $0.024^{* *}$ & & $0.047^{* * *}$ & & $0.054^{* * *}$ & & $0.051 * * *$ \\
\hline & Vocational school & & $0.034 * * *$ & & 0.015 & & $0.033^{* * *}$ & & $0.060 * * *$ & & $0.034 * * *$ \\
\hline & High school & & $0.061 * * *$ & & $0.046^{* * *}$ & & $0.067^{* * *}$ & & $0.060 * * *$ & & $0.063 * * *$ \\
\hline & More than high school & & $0.093^{* * *}$ & & $0.075^{* * *}$ & & $0.100 * * *$ & & $0.097 * * *$ & & $0.089 * * *$ \\
\hline \multirow[t]{4}{*}{ Income } & Quartile 1 & & Ref & & Ref & & Ref & & Ref & & Ref \\
\hline & Quartile 2 & & $0.036 * * *$ & & $0.061 * * *$ & & $0.033^{* * *}$ & & $0.029 * * *$ & & $0.030 * * *$ \\
\hline & Quartile 3 & & $0.044^{* * *}$ & & $0.068 * * *$ & & $0.047^{* * *}$ & & $0.040 * * *$ & & $0.042 * * *$ \\
\hline & Quartile 4 & & $0.069 * * *$ & & $0.104 * * *$ & & $0.059 * * *$ & & $0.073 * * *$ & & $0.060 * * *$ \\
\hline \multirow[t]{4}{*}{ Year of survey } & 1997 & Ref & Ref & & & & & & & & \\
\hline & 2000 & $0.010^{* *}$ & $0.013^{* * *}$ & & & & & & & & \\
\hline & 2003 & $-0.011 * * *$ & $-0.018 * * *$ & & & & & & & & \\
\hline & 2006 & $-0.046 * * *$ & $-0.048 * * *$ & & & & & & & & \\
\hline \multicolumn{2}{|c|}{ Predicted probability of smoking } & 0.262 & 0.259 & 0.278 & 0.274 & 0.284 & 0.282 & 0.258 & 0.256 & 0.223 & 0.221 \\
\hline \multicolumn{2}{|c|}{ Number of observations } & 87331 & 87331 & 24076 & 24076 & 22213 & 22213 & 20165 & 20165 & 20877 & 20877 \\
\hline
\end{tabular}

Source: OVE survey 1997-2006.

Note: marginal effects obtained from Probit models. Significance levels are respectively $1 \%\left({ }^{* * *}\right), 5 \%\left({ }^{* *}\right)$ and $10 \%\left({ }^{*}\right)$. 
Table 3. OLS estimates of the number of cigarettes per smoker (among smokers)

\begin{tabular}{|c|c|c|c|c|c|c|c|c|c|c|c|}
\hline \multirow{2}{*}{\multicolumn{2}{|c|}{ Variables }} & \multicolumn{2}{|l|}{$1997-2006$} & \multicolumn{2}{|l|}{1997} & \multicolumn{2}{|l|}{2000} & \multicolumn{2}{|l|}{2003} & \multicolumn{2}{|l|}{2006} \\
\hline & & $(1 \mathrm{~A})$ & (1B) & $(2 \mathrm{~A})$ & $(2 B)$ & $(3 A)$ & $(3 B)$ & $(4 A)$ & (4B) & $(5 A)$ & $(5 B)$ \\
\hline \multicolumn{2}{|l|}{ Constant } & -5.994 & -7.014 & -5.082 & -7.198 & $-20.297 * *$ & $-20.803 * *$ & -0.786 & -2.108 & 0.137 & 0.237 \\
\hline \multicolumn{12}{|c|}{ Student's characteristics } \\
\hline \multicolumn{2}{|c|}{ Girls } & $-0.390 * * *$ & $-0.412 * * *$ & $-0.761 * * *$ & $-0.776 * * *$ & $-0.410 * *$ & $-0.432 * * *$ & 0.195 & 0.165 & $-0.406 * *$ & $-0.417^{* *}$ \\
\hline \multicolumn{2}{|l|}{ Age } & $1.191 * * *$ & $1.272 * * *$ & 1.122 & 1.276 & $2.503 * * *$ & $2.553 * * *$ & 0.537 & 0.665 & 0.455 & 0.464 \\
\hline \multicolumn{2}{|c|}{ Age squared (/100) } & $-0.020 * *$ & $-0.022 * *$ & -0.019 & -0.023 & $-0.051 * *$ & $-0.052 * * *$ & -0.005 & -0.008 & -0.003 & -0.003 \\
\hline \multicolumn{2}{|c|}{ Number of siblings } & $-0.057^{*}$ & $-0.070 * *$ & $-0.135^{* *}$ & $-0.145^{* *}$ & -0.085 & -0.106 & 0.075 & 0.060 & -0.055 & -0.067 \\
\hline \multirow[t]{4}{*}{ High school } & Without distinction & Ref & Ref & Ref & Ref & Ref & Ref & Ref & Ref & Ref & Ref \\
\hline & Cum laude & $-0.616^{* * *}$ & $-0.613^{* * *}$ & $-0.543 * * *$ & $-0.554 * * *$ & $-0.713 * * *$ & $-0.693 * * *$ & $-0.847 * * *$ & $-0.875^{* * *}$ & $-0.341^{*}$ & -0.300 \\
\hline & Magna cum laude & $-0.939 * * *$ & $-0.927 * * *$ & $-1.112^{* * *}$ & $-1.193 * * *$ & $-0.463^{*}$ & -0.411 & $-1.025^{* * *}$ & $-1.043 * * *$ & $-1.200 * * *$ & $-1.134^{* * *}$ \\
\hline & Summa cum laude & $-1.152 * * *$ & $-1.175 * * *$ & $-1.945 * * *$ & $-2.087 * * *$ & -1.012 & -1.070 & -0.879 & -0.852 & -0.956 & -0.883 \\
\hline \multirow[t]{4}{*}{ Income } & Quartile 1 & Ref & Ref & Ref & Ref & Ref & Ref & Ref & Ref & Ref & Ref \\
\hline & Quartile 2 & $0.763 * * *$ & $0.699 * * *$ & $0.923 * * *$ & $0.879 * * *$ & $0.609 * * *$ & $0.534 * *$ & $0.608^{* *}$ & $0.548^{* *}$ & $0.713 * * *$ & $0.628^{* *}$ \\
\hline & Quartile 3 & $0.995 * * *$ & $0.881 * * *$ & $1.161 * * *$ & $1.037 * * *$ & $0.619 * * *$ & $0.491^{* *}$ & $1.007 * * *$ & $0.923 * * *$ & $0.991 * * *$ & $0.842 * * *$ \\
\hline & Quartile 4 & $1.301 * * *$ & $1.136 * * *$ & $1.615^{* * *}$ & $1.433 * * *$ & $1.152 * * *$ & $0.996 * * *$ & $1.186 * * *$ & $1.031 * * *$ & $1.007 * * *$ & $0.831 * * *$ \\
\hline \multicolumn{12}{|c|}{ Parental characteristics } \\
\hline \multicolumn{2}{|l|}{ Living alone } & & $0.904 * * *$ & & $1.170 * * *$ & & $0.818^{* * *}$ & & $0.865^{* * *}$ & & $0.676 * * *$ \\
\hline \multicolumn{2}{|l|}{ Unemployed } & & $0.386 * * *$ & & $0.581 * * *$ & & 0.132 & & 0.162 & & $0.661 * * *$ \\
\hline \multirow[t]{5}{*}{ Education } & Primary school & & Ref & & Ref & & Ref & & Ref & & Ref \\
\hline & Secondary education & & -0.065 & & -0.011 & & 0.090 & & 0.020 & & -0.540 \\
\hline & Vocational school & & $-0.262^{*}$ & & -0.215 & & -0.400 & & -0.192 & & -0.401 \\
\hline & High school & & -0.250 & & -0.213 & & -0.330 & & -0.132 & & -0.506 \\
\hline & More than high school & & -0.229 & & 0.223 & & $-0.599 *$ & & -0.276 & & -0.494 \\
\hline \multirow{5}{*}{$\begin{array}{l}\text { Unemployed } \\
\text { Income }\end{array}$} & & & 0.064 & & 0.169 & & 0.191 & & -0.186 & & -0.026 \\
\hline & Quartile 1 & & Ref & & Ref & & Ref & & Ref & & Ref \\
\hline & Quartile 2 & & 0.064 & & 0.169 & & 0.191 & & -0.186 & & -0.026 \\
\hline & Quartile 3 & & 0.100 & & 0.201 & & 0.143 & & -0.077 & & -0.126 \\
\hline & Quartile 4 & & $0.518^{* * *}$ & & $0.552^{* *}$ & & $0.800 * * *$ & & $0.468^{*}$ & & 0.109 \\
\hline \multirow[t]{4}{*}{ Year of survey } & 1997 & Ref & Ref & & & & & & & & \\
\hline & 2000 & $-0.430 * * *$ & $-0.368 * * *$ & & & & & & & & \\
\hline & 2003 & $-1.226 * * *$ & $-1.222 * * *$ & & & & & & & & \\
\hline & 2006 & $-1.817^{* * *}$ & $-1.760 * * *$ & & & & & & & & \\
\hline \multicolumn{2}{|c|}{ Number of observations } & 23312 & 23312 & 6761 & 6761 & 6411 & 6411 & 5354 & 5354 & 4786 & 4786 \\
\hline
\end{tabular}

Source: OVE survey 1997-2006.

Note: estimates from OLS models estimated on the subsample of smokers. Significance levels are respectively $1 \%(* * *), 5 \%(* *)$ and $10 \%\left({ }^{*}\right)$. 
Table 4. Income elasticity of smoking

\begin{tabular}{|c|c|c|c|c|c|c|}
\hline \multicolumn{2}{|l|}{ Year of survey } & $\begin{array}{l}1997- \\
2006\end{array}$ & 1997 & 2000 & 2003 & 2006 \\
\hline \multicolumn{7}{|l|}{ (1) All students } \\
\hline \multicolumn{7}{|c|}{ Income elasticity of smoking participation } \\
\hline \multirow[t]{2}{*}{ (1A) No parental control } & Student's income elasticity & 0.178 & 0.152 & 0.168 & 0.195 & 0.196 \\
\hline & & $(0.008)$ & $(0.015)$ & $(0.012)$ & $(0.016)$ & $(0.016)$ \\
\hline \multirow[t]{4}{*}{ (1B) With parental control } & Student's income elasticity & 0.163 & 0.135 & 0.157 & 0.181 & 0.180 \\
\hline & & (0.009) & $(0.012)$ & $(0.012)$ & $(0.016)$ & $(0.013)$ \\
\hline & Parental income elasticity & 0.159 & 0.232 & 0.095 & 0.179 & 0.188 \\
\hline & & $(0.010)$ & $(0.025)$ & $(0.024)$ & $(0.021)$ & $(0.028)$ \\
\hline \multicolumn{7}{|c|}{ Income elasticity of cigarettes consumption } \\
\hline \multirow[t]{2}{*}{ (1C) No parental control } & Student's income elasticity & 0.060 & 0.066 & 0.055 & 0.068 & 0.049 \\
\hline & & $(0.005)$ & $(0.010)$ & $(0.012)$ & $(0.016)$ & $(0.013)$ \\
\hline \multirow[t]{4}{*}{ (1D) With parental control } & Student's income elasticity & 0.051 & 0.056 & 0.046 & 0.059 & 0.039 \\
\hline & & $(0.007)$ & $(0.010)$ & $(0.011)$ & $(0.011)$ & $(0.016)$ \\
\hline & Parental income elasticity & 0.057 & 0.059 & 0.057 & 0.055 & 0.034 \\
\hline & & $(0.011)$ & $(0.016)$ & $(0.016)$ & $(0.023)$ & $(0.025)$ \\
\hline \multicolumn{7}{|l|}{ (2) Male students } \\
\hline \multicolumn{7}{|c|}{ Income elasticity of smoking participation } \\
\hline \multirow[t]{2}{*}{ (2A) No parental control } & Student's income elasticity & 0.146 & 0.141 & 0.154 & 0.121 & 0.155 \\
\hline & & $(0.012)$ & $(0.024)$ & $(0.023)$ & $(0.036)$ & $(0.030)$ \\
\hline \multirow[t]{4}{*}{ (2B) With parental control } & Student's income elasticity & 0.137 & 0.128 & 0.148 & 0.111 & 0.146 \\
\hline & & $(0.013)$ & $(0.014)$ & $(0.027)$ & $(0.033)$ & $(0.029)$ \\
\hline & Parental income elasticity & 0.158 & 0.216 & 0.101 & 0.154 & 0.195 \\
\hline & & $(0.025)$ & $(0.033)$ & $(0.032)$ & $(0.043)$ & $(0.040)$ \\
\hline \multicolumn{7}{|c|}{ Income elasticity of cigarettes consumption } \\
\hline \multirow[t]{2}{*}{ (2C) No parental control } & Student's income elasticity & 0.071 & 0.067 & 0.044 & 0.116 & 0.083 \\
\hline & & $(0.011)$ & $(0.013)$ & $(0.017)$ & $(0.020)$ & $(0.019)$ \\
\hline \multirow[t]{4}{*}{ (2D) With parental control } & Student's income elasticity & 0.063 & 0.054 & 0.038 & 0.111 & 0.075 \\
\hline & & $(0.010)$ & $(0.017)$ & (0.019) & $(0.024)$ & $(0.023)$ \\
\hline & Parental income elasticity & 0.066 & 0.084 & 0.062 & 0.026 & 0.072 \\
\hline & & $(0.018)$ & $(0.027)$ & $(0.040)$ & $(0.034)$ & $(0.040)$ \\
\hline \multicolumn{7}{|l|}{ (3) Female students } \\
\hline \multicolumn{7}{|c|}{ Income elasticity of smoking participation } \\
\hline \multirow[t]{2}{*}{ (3A) No parental control } & Student's income elasticity & 0.196 & 0.158 & 0.178 & 0.240 & 0.217 \\
\hline & & $(0.009)$ & $(0.017)$ & $(0.021)$ & $(0.018)$ & $(0.023)$ \\
\hline \multirow[t]{4}{*}{ (3B) With parental control } & Student's income elasticity & 0.177 & 0.138 & 0.162 & 0.223 & 0.195 \\
\hline & & $(0.011)$ & $(0.018)$ & $(0.017)$ & $(0.022)$ & $(0.024)$ \\
\hline & Parental income elasticity & 0.162 & 0.244 & 0.094 & 0.195 & 0.187 \\
\hline & & $(0.013)$ & $(0.028)$ & $(0.031)$ & $(0.034)$ & $(0.041)$ \\
\hline \multicolumn{7}{|c|}{ Income elasticity of cigarettes consumption } \\
\hline \multirow[t]{2}{*}{ (3C) No parental control } & Student's income elasticity & 0.052 & 0.064 & 0.066 & 0.043 & 0.020 \\
\hline & & $(0.008)$ & $(0.012)$ & $(0.011)$ & $(0.019)$ & $(0.012)$ \\
\hline \multirow[t]{4}{*}{ (3D) With parental control } & Student's income elasticity & 0.041 & 0.054 & 0.053 & 0.032 & 0.007 \\
\hline & & $(0.009)$ & $(0.010)$ & $(0.014)$ & $(0.018)$ & $(0.018)$ \\
\hline & Parental income elasticity & 0.050 & 0.045 & 0.051 & 0.065 & 0.021 \\
\hline & & $(0.009)$ & $(0.019)$ & $(0.018)$ & $(0.027)$ & $(0.025)$ \\
\hline
\end{tabular}

Source: OVE survey 1997-2006.

Note: elasticities are calculated at sample means. Bootstrapped standard errors are in parentheses, with 200 replications. The regressions include cubic profiles for income along with the covariates introduced in Tables 2 and 3. 
Table 5. Smoking-income selectivity-corrected derivatives

\begin{tabular}{cccccc}
\hline Year of survey & $1997-2006$ & 1997 & 2000 & 2003 & 2006 \\
\hline Parental income (/1000) & & & & \\
Uncorrected OLS derivative & 0.147 & 0.167 & 0.179 & 0.123 & 0.079 \\
& $(0.024)$ & $(0.047)$ & $(0.044)$ & $(0.048)$ & $(0.054)$ \\
AlO corrected derivative & 0.585 & 0.848 & 0.417 & 0.559 & 0.556 \\
& $(0.040)$ & $(0.088)$ & $(0.072)$ & $(0.079)$ & $(0.098)$ \\
Student's income (/1000) & & & & & 0.265 \\
Uncorrected OLS derivative & 0.542 & 0.951 & 0.647 & 0.444 & $(0.165)$ \\
& $(0.080)$ & $(0.190)$ & $(0.173)$ & $(0.126)$ & 1.830 \\
AlO corrected derivative & 2.252 & 3.315 & 2.118 & 1.923 & $(0.270)$ \\
\hline & $(0.143)$ & $(0.308)$ & $(0.329)$ & $(0.226)$ & 20877 \\
Number of students & 87331 & 24076 & 22213 & 20165 & 2078 \\
Number of smokers & 23312 & 6761 & 6411 & 5354 & 4786 \\
\hline
\end{tabular}

Source: OVE survey 1997-2006.

Note: The uncorrected smoking-income derivatives are from OLS regressions. The corrected derivatives are calculated using the estimator described in Altonji et al. (2011). Bootstrapped standard errors are in parentheses, with 200 replications. Our regressions also include the list of covariates introduced in Tables 2 and 3. 
Table 6. Probit estimates of the probability of smoking and parental smoking - marginal effects

\begin{tabular}{|c|c|c|c|c|c|}
\hline \multicolumn{2}{|l|}{ Variables } & \multicolumn{2}{|c|}{ (1) } & \multicolumn{2}{|c|}{$(2)$} \\
\hline \multirow[t]{4}{*}{ Student's income } & Quartile 1 & Ref & & Ref & \\
\hline & Quartile 2 & $0.061^{* * *}$ & (6.47) & $0.061 * * *$ & (6.53) \\
\hline & Quartile 3 & $0.103^{* * *}$ & (10.66) & $0.103^{* * *}$ & $(10.58)$ \\
\hline & Quartile 4 & $0.119 * * *$ & (11.93) & $0.119 * * *$ & $(12.25)$ \\
\hline \multirow[t]{4}{*}{ Parental income } & Quartile 1 & Ref & & Ref & \\
\hline & Quartile 2 & $0.029 * * *$ & (3.11) & $0.029 * * *$ & $(3.22)$ \\
\hline & Quartile 3 & $0.040 * * *$ & (4.15) & $0.041 * * *$ & $(4.22)$ \\
\hline & Quartile 4 & $0.073 * * *$ & (6.93) & $0.075^{* * *}$ & (6.91) \\
\hline \multicolumn{2}{|c|}{ Parental smoking } & & & $0.060 * * *$ & $(2.72)$ \\
\hline \multicolumn{2}{|c|}{ Other family background characteristics } & YES & & YES & \\
\hline \multicolumn{2}{|c|}{ Number of observations } & 20165 & & 20165 & \\
\hline
\end{tabular}

Source: OVE 2003 survey and Health 2003 survey.

Note: our regressions also include the list of covariates introduced in Tables 2 and 3. 